\title{
AS FONTES DE DUARTE PACHECO PEREIRA NO "ESMERALDO DE SITU ORBIS" (III).
}

\section{(Continuação) .}

Duarte Pacheco Pereira menciona uma única vez, no Esmeraldo de situ orbis, Sacrobosco e o seu Tratado da Esfera. Esta citação aparece no Capítulo 1 do Livro IV, juntamente com uma referência ao De Situ Orbis de Pompônio Mela e outra a Plínio:

"Pompônio Mela, no princípio do seu segundo livro e assi no meio do terceiro De Situ Orbis, e Mestre João de Sacrobosco, Ingrês, excelente autor na arte da astronomia, no fim do terceiro capítulo de seu Tratado da Esfera, cada um destes em seu lugar, ambos disseram que as partes da equinocial eram inabitáveis pola muito grande quentura do sol; donde parece que, segundo sua tenção, aquela tórrida zona por esta causa se não podia navegar, pois que a fortaleza do sol impedia não haver i habitação de gente; o que tudo isto é falso; certamente temos muita razão de nos espantar de tão excelentes homens, como estes foram, e assi Plínio e outros autores que isto mesmo afirmaram, cairem em tamanho erro como neste caso disseram, porque eles todos confessam a India ser verdadeiramente ouriental e povorada de gente sem número; e como assim seja que o verdadeiro ouriente é o círculo, da equinocial, que por Guiné e pola India passa e com a maior parte dela tem vizinhança, craramente se mostra ser falso o que escreveram...".

Mas, apesar de ser esta a única citação do nome de Sacrobosco e do título da sua obra, a verdade é que através do texto de Duarte Pacheco Pereira encontramos uma dúzia de passos em que a influência do Trataldo da Esfera é bem nítida.

Antes de entrarmos na confrontação dêstes passos do Esmeraldo com o texto da obra de Sacrobosco, procuremos saber - o que talvez não seja impossível - de que edição ou manuscrito do Tratado da Esfera se serviu Duarte Pacheco. 
Logo no início dêste estudo, a propósito de um pequeno passo do Prólogo da obra de Pacheco, chegamos à conclusão que 0 autor do Esmeraldo teria tido conhecimento da carta de Munzer a D. João II, escrita em Nuremberg, a 14 de julho de 1493. Admitimos então a hipótese de Pacheco a ter conhecido ainda na sua forma manuscrita, embora já traduzida, e admitimos também, como a hipótese mais provável, que êle a tenha conhecido já impressa na coletânea comumente nomeada por Regimento de Munich, muito embora em edição anterior à daquele exemplar que Joaquim Bensaude descobriu e publicou com o título de Regimento do Estrolabio e do Quadrante - Tractado da Spera do Mundo, em Munique, em 1914, em Reproduction fac-similé /du seul exemplaire connu appartenant à la Bibliothèque Royale de Munich.

Ora êste Regimento de Munich, como já dissemos, além da carta de Munzer a D. João II, e do Regimento do Estrolabio e do Quadrante, contém uma tradução para a língua portuguêsa do Tratado da Esfera. Daí podermos admitir, como hipótese, Duarte Pacheco Pereira ter-se servido desta tradução em língua portuguêsa da obra de Sacrobosco. E parecenos que se trata de hipótese tanto mais verossímil quanto na parte final dêste estudo nos propomos demonstrar, e então de maneira insofismável, que Pacheco se serviu de uma tritdução castelhana do De Situ Orbis de Pompônio Mela, e de uma tradução italiana da História Natural de Plínio. Daqui a concluir que Duarte Pacheco preferia os textos em línguas vulgares aos textos em latim, vai um pequeno passo.

Mas, assim mesmo, seremos obrigados a considerar outras hipóteses. Teria Duarte Pacheco, contra aquilo que afinal parece mais verossímil, utilizado um texto latino da obra de Sacrobosco? E ao admiti-lo, pensamos nas variadas edições latinas da época, como as de Paris, de 1494 (68), 1498 (69), 1500 (70), ou as de Veneza, de 1478 (71), 1482 (72), 1485 (73), 1488 (74), $1490(75), 1499$ (76), 1501 (77).

(68). - Joannis de Sacro Bosco Sphaera mund, una cum additionibus insertis ac familiarissima textus expositione Petri de Alliaco, Parisils, per W. Hopyl, 1494.

(69). - Uberrimum Joannis de Sacro Boseo Sphaere mundi commentum Petri Cirnelli, insertis etiam questionibus Petri de Aliaco, Parisiis, J. Petit, impensis G. Mercatoris, 1498 .

(70). - Textus de Sphera Johannis de Sacro Bosco, cum additione..., Parisíis, per W. Hopyl, 1500.

(71). - Joannis de Sacro Bosco Sphaera mundi, vel Tractatus de Sphaera Gerard Cremonensis. Theorica planetarum. Venetiis, per F. Renner de Hailbrun, 1478. 
Finalmente, poderíamos ainda admitir a utilização por Duarte Pacheco Pereira do único texto latino do Tratado da Esfera de Sacrobosco que se saiba ter existido em Portugal no século XV: um manuscrito oriundo da Abadia de Aicobaça e que hoje se encontra na Biblioteca Nacional, em Lisboa (78) .

Comecemos por esta última hipótese. Pacheco teria utilizado êste manuscrito, único texto latino da obra de Sacrobosco que se saiba ter existido em Portugal no século XV?

Num dos doze passos do Esmeraldo (Capítulo 1 do Livro I) onde nos parece ser nítida a influência do Tratado da Esfera, pode ler-se:

" $E$ por tal modo é o assento do orbe composto, que se algum homem podesse furar a terra e lançasse ua pedra da sua soprifície, cuidando que passaria do outro cabo, ela não iria senão até o centro, e ali estaria queda,

(72). - Joannis de Sacro Boseo Sphaera mundi. Joannis de Monteregio Disputationes contra Cremonensia in planetarum theoricas deliramenta. Georgii Purbachii In motus planetarum theoricae. Venetiis, E. Ratdolt, 1482.

(73). - Thidem, 1485.

(74). - Ibidem, 1488 (J .Santritter e H. de Sanctis).

(75). - Ibidem, 1490.

(76). - Joannis de Sacro Bosco Sphaera mundi, cum tribus commentis nuper editis, videlicet Cicehi Esculani, Francisei Capuani de Manfredonia et Jacobi Fabri Stapulensis. Theoricae novae. planetarum Georgii Purbachii et in eas Francisci Capuani de Manfredonia expositio. Venetiis, per S. Papiensem, 1499.

(77). - Sphaera mundi Johannis de Sacro Bosco..., Venetiis, per Jo. Baptista Sessa, anno salutis 1501, die vero 3 decembris. Além destas edições da obra de Sacrobosco, consultamos ainda: Iean de Sacrobosco - La Sphère, Pa. ris, 1576; The Sphere of Sacrobosco and Its Commentators. The University of Chicago Press, 1949 (Ed. by Lynn Thorndike).

(78) . - Reservados, CCCXXXIII-385, fls. 21-26. Este manuscrito foi editado por Luís Mendonça de Albuquerque: Sôbre um manuscrito quatrocentista do "Tratado da Esfera" de Sacrobosco, in "Revista da Faculdade de Ciências da Universidade de Coimbra". Volume XXVIII, Coimbra, 1959. O autor dêste trabalho, muito provàvelmente enganado pelo índice onomástico da edição do Esmeraldo de situ orbis de Epiphanio da Silva Dias, em que Sacrobosco não aparece na letra $S$ mas na letra $J$ (João), foi levado na sua Introdução a afirmar que no Esmeraldo de situ orbis de Duarte Paco Pereira não se encontra o menor indício de uma leitura, mesmo superficial, de Sacrobosco (p. 13). Em publicação mais recente, 0 primeiro guia náutico português e o problema das latitudes na marinha dos séculos XV e XVI (in "Revista da Universidade de Coimbra", volume XIX, Coimbra, 1960), Luís Mendonça de Albuquerque retomando êste mesmo assunto, afirma que Pacheco cita Sacrobosco uma só vez, e à parte esta citação ocasional, não se encontra no Esmeraldo nenhum outro passo que possa deixar supor que Pacheco leu o Tratado da Esfera (págs. 13-14 đa Separata). Como se vê, discordamos neste detalhe do nosso amigo Luís Mendonça de Albuquerque, o que não nos impede de reconhecermos a extraordinária importância dos seus trabalhos de História da Ciência em Portugal, em vírtude dos quais o julgamos um digno sucessor de Luciano Pereira da Silva. 
porque ali é o mais baixo e o meio, e deste lugar pera qualquer parte seria subir, que é impossivel e contra natureza nenhua cousa pesada poder ir pera cima e mover-se do centro para a circunferência;...".

Ora, o manuscrito latino do século XV é um texto mutilado da obra de Sacrobosco. Faltam o Capítulo IV, a parte final do Capítulo III, e alguns passos, em certos casos bastante longos, estando entre êstes aquêle que corresponde ao texto do Esmeraldo que acabamos de citar. E assim, êste exemplo basta-nos para podermos afirmar que Duarte Pacheco Pereira não se serviu dêste manuscrito latino. Em contrapartida encontramos uma correspondência que podemos considerar perfeita, entre êste texto do Esmeraldo e o seguinte passo da tradução portuguêsa da obra de Sacrobosco inserta no chamado Regimento de Munich:

"A terra por seu grande pesume estaa jmouell em meo do firmamento: por duas razoões. A primeira he: que toda a cousa pesada em summo graao deseja ho centro: e ally folga: e çeça de se mouer. $E$ ha segunda rezam he: que toda a cousa que se moue do cemtro a circunferencia sobre a terra: se se moue soberia: ho qual he jmpossiuel: e contra ha natura da cousa pesada em summo grao como he ha terra" (79).

Tomemos agora a segunda hipótese atrás enunciada: a de que Pacheco teria lido e utilizado um qualquer texto latino da época do célebre Tratado de Sacrobosco. Para podermos avaliar até que ponto esta hipótese se confirma ou não, somos levados a voltar ao texto do Capítulo 1 do Livro IV do Esmeraldo, inicialmente citado, e que corresponde à única citação que Duarte Pacheco Pereira faz de Sacrobosco e do seu Tratado da Esfera, juntamente com uma referência ao De Situ Orbis de Pompônio Mela, e outra a Plínio:

"Pompónio Mela, no princípio do seu segundo livro e assi no meio do terceiro De Situ Orbis, e Mestre João de Sacrobosco, Ingrês, excelente autor na arte da astronomia, no fim do terceiro capitulo do seu Tratado da Esfera, cada um destes em seu lugar, ambos disseram que as partes da equinocial eram inabitáveis pola muito grande quentura do sol; donde parece que, segundo sua tenção, aquela tórrida zona por esta causa se não podia navegar, pois que a fortaleza do sol impedia não haver i habitação de

(79). - Regimento do Estrolabio e do Quadrante - Tractado da Spera do Mundo, Munich, 1914, pág. 34 (Edição de Joaquim Bensaúde). 
gente; o que tudo isto é falso; certamente temos muita razão de nos espantar de tão excelentes homens, como estes foram, e assi Plínio e outros autores que isto mesmo afirmaram, cairem em tamanho erro como neste caso disseram, porque eles todos confessam a India ser verdadeiramente ouriental e povorada de gente sem nứmero; e como assim seja que o verdadeiro ouriente é o círculo da equinocial, que por Guiné e pola India passa e com a maior parte dela tem vizinhança, craramente se mostra ser falso o que escreveram;...".

Como vemos, Duarte Pacheco indica o fim do Terceiro Capítulo do Tratado da Esfera, no qual podemos ler, em qualquer das edições latinas atrás citadas:

“...illius propinque equinoctiali inhabitabiles sunt propter nimium calorem. Similiter partes eius propinque polo arctico inhabitabiles sunt propter nimiam frigiditatem".

Mas um passo semelhante, e até talvez mais próximo das palavras de Duarte Pacheco, podemos ver, não no fim do Terceiro Capítulo, mas no fim do Segundo:

"Illa igit çona que est inter duos tropicos dicit inhabitabilis propter calorem solis discurrentis semper inter tropicos".

Poderemos admitir um êrro de citação da parte de Duarte Pacheco que afinal não é o único através da sua obra. Neste mesmo texto êle incorre em êrro semelhante na citação que faz do De Situ Orbis de Pompônio Mela, como veremos quando nos ocuparmos desta fonte do seu Esmeraldo. Também, como atrás mostramos, Duarte Pacheco incorre em êrro do mesmo gênero na única citação que faz da obra de Vicente de Beauvais, quando confunde o $\mathbf{C}$ que indica Capítulo, com o $\mathbf{C}$ que significa cem em números romanos. Aliás o êrro de citação no texto de Pompônio Mela pode talvez explicar-se se soubermos: 1) que Pacheco leu o De Situ Orbis pela tradução castelhana de Mestre João Faras, como demonstraremos na parte final dêste estudo; 2) que ṇo texto manuscrito da tradução de Mestre João Faras não existe a separação em Livros, não sendo mesmo os capítulos numerados, e até só havendo títulos nos primeiros Capítulos do Livro I. Ora coisa semelhante parecenos poder ter ocorrido com a citação do Tratado da Esfera, se admitirmos como hipótese ter-se Duarte Pacheco servido da tradução portuguêsa inserta no chamado Regimento de $\mathbf{M u}$ 
nich. No exemplar que dêste conhecemos, a indicação dos Capítulos não é muito clara, pois o texto muito cerrado e sem espaços brancos não facilita uma distinção rápida e segura. E se atentarmos nesta tradução portuguêsa do texto de Sacrobosco, chegaremos ainda mais nitidamente à conclusão que Duarte Pacheco se deve referir ao final do Segundo Capítulo, e não ao final do Terceiro. Vejamos os dois passos em questão.

No final do Terceiro Capítulo, lemos na tradução portuguêsa:

"Ca a parte ao equinoçiall nam he morada: por muyta quentura, a parte propinqua ao pollo nam he morada por muyto frio" (80).

No final do Segundo Capítulo, lemos:

"A plagaa do meo sobiecta aa torrida zona amtre os dous tropicos se diz nom morada por ha gramde quentura do sol" (81).

Embora o assunto não difira de um passo para o outro, a verdade é que o segundo texto parece-nos mais próximo das palavras de Pacheco.

Afastada a hipótese de Duarte Pacheco se ter servido do manuscrito latino do século XV, oriundo da Abadia de Alcobaça, e agora na Biblioteca Nacional, em Lisboa, restam-nos, como já dissemos, duas possibilidades: ou Pacheco se serviu de qualquer uma das edições latinas da época, ou então da tradução portuguêsa inserta no exemplar que conhecemos do chamado Regimento de Munich. Esta última hipótese parece-nos indiscutivelmente a mais provável. No texto da tradução portuguêsa aparece a expressão grande quentura do sol, expressão reproduzida por Pacheco no texto do Esmeraldo em questão, e ainda noutro passo do Livro Segundo, Capítulo 11 de que nos ocuparemos a seguir. Ora os textos latinos dão, em vez de grande quentura do sol, a expressão calorem solis.

$O$ fato de Duarte Pacheco ter empregado a palavra inabitáveis, em vez da expressão nom morada, da tradução portuguêsa do exemplar de Munique, levou Luís Mendonça de Albuquerque (82) a concluir que êle não se serviu desta tradução, mas certamente de um texto latino. Mas Luís Mendonça

(80). - Midem, págs. 54-55.

(81). - Ibidem, pág. 43.

(82). - O primeiro guia náutico português e o problema das latitudes na marinha dos séculos XV e XVI, in "Revista da Universidade de Colmbra", Volume XIX, Colmbra, 1960, págs. 13-14 da Separata. 
de Albuquerque não toma em conta um pormenor que explica sobejamente êste fato. Duarte Pacheco cita neste mesmo passo, e a propósito do mesmo assunto, além de Sacrobosco, Plínio e Pompônio Mela. Ora no texto latino de Pompônio Mela vemos a palavra inhabitabilem, e no texto castelhano, traduzido por Mestre João Faras, de que se serviu Pacheco, vemos a palavra jnhabitables. Esta palavra foi Pacheco buscá-la a Pompônio Mela, tal como foi buscar à tradução portuguêsa de Sacrobosco inserta no chamado Regimento de Munich a expressão grande quentura do sol.

A comparação de textos até aqui feita leva-nos a pensar que, com tôda a probabilidade, Duarte Pacheco Pereira deve ter tido conhecimento, tanto da carta de Munzer a D. João II, quanto do Tratado da Esfera de Sacrobosco, através de um exemplar da coletânea conhecida por Regimento de Munich. Talvez não na edição a que pertence o exemplar descoberto em Munique por Joaquim Bensaúde, dado que êle foi impresso por Hermão de Campos que só teria começado a trabalhar como impressor em Portugal em 1509, data posterior à redação da obra de Pacheco, mas muito provàvelmente em exemplar de edição anterior, sabendo nós que Otto Hartig, antigo conservador da Biblioteca Real de Munique, afirma que o único exemplar conhecido não pertence à edição princeps.

Duarte Pacheco Pereira aborda, em Capítulos anteriores da sua obra, embora de maneira sucinta, o assunto central do último texto por nós citado, em que se pode ver a única referência a Sacrobosco e ao Tratado da Esfera. Assim é no Capítulo 10, do Livro II:

“...e esta terra é muito vezinha do círculo da equinocial, da qual os antigos disseram que era inabitável $\mathbf{e}$ nós por experiência achamos o contrário".

E também no Capítulo 11 do mesmo Livro II:

"A experiência nos faz viver sem engano das abusões e fábulas que alguns dos antigos cosmógrafos. escreveram acêrca da descrição da terra e do mar, os quais disseram que tôda a terra que jaz debaixo do círculo da equinocial era inabitável pola grande quentura do sol, e isto achamos falso e pelo contrário...".

Notemos que já neste texto Duarte Pacheco emprega a expressão grande quentura do sol.

Dois passos mais existem na obra de Duarte Pacheco que não desconfirmam as conclusões a que até agora chegamos. 
São dois passos por nós já atrás citados, pois êles são demonstrativos de que Pacheco não conheceu diretamente Alfragano, mas teve dêste conhecimento através do Tratado da Esfera de Sacrobosco. O primeiro dêstes textos pode ver-se no Capítulo 33 do Livro I:

“...e por isso devemos notar o que diz Alfragano, que os Etiópios o seu inverno e verão são de ua mesma compleição;...".

As várias edições latinas, da obra de Sacrobosco, da época de Duarte Pacheco, já mencionadas, dão-ños:

"Et hoc est quod dicit Alfraganus quod estas et hyemis scilicet nostre sunt illis unius et eiusdem complexionis:...".

A tradução portuguêsa, donde julgamos ter Pacheco tirado a citação, dá-nos:

"Esto he o que diz Alfragano que a estes ho jnuerno e o estio sam de hua mesma compriçam" (83).

Este passo em que Sacrobosco cita Alfragano aparece ainda no Esmeraldo umas páginas mais adiante, no Capítulo 2 do Livro II:

"...e isto é o que diz Alfragano desta terra e moradores dela, que aos Etiópios o verão e o inverno ambos são de ua mesma compleição;...".

Pacheco repete a afirmação do Capítulo 33 do Livro I, apenas com a insignificante diferença que representa a inversão da ordem das palavras inverno e verão.

Outros passos da obra de Duarte Pacheco revelam a influência do Tratado da Esfera de Sacrobosco, e não desconfirmam ter êle utilizado a tradução portuguêsa inserta no chamado Regimento de Munich, se bem que em edição anterior àquela a que pertence 0 único exemplar conhecido.

Assim, logo no Capítulo 1 do Livro I, vemos todo um passo cuja fonte é indubitàvelmente o De Situ Orbis de Pompônio Mela, mas que na parte final revela influência do texto de Sacrobosco:

(83). - Regimento do Estrolabio e do Quadrante - Tractado da Spera do Mundo, Munique, 1914, pág. 51 (Ediçāo de Joaquím Bensaúde) . 
"...e isto que ora brevemente é dito, sòmente toca aos círculos superiores; e em-adendo mais na matéria, afirmaram que a terra neste meio é posta como centro e de toda parte é cingida pelo mar, e ela mesma em duas partes, que hemispérios são chamados, desde ouriente dividida até oucidente, volvendo em ouriente, per cinco zonas é repartida; a zona do meio, que equinocial se chama, ou cinta do primeiro movimento, pelo grande ardor do sol é assaz d'afadigada...".

A expressão, mento",

"equinocial se chama, ou cinta do primeiro movi-

é muito provàvelmente proveniente do Tratado da Esfera de Sacrobosco, na sua tradução em língua portuguêsa:

"chamase a tambem a equinociall cinta do primeiwo mouimento porque ho parte por ho meo distando jguallmente dos polos do mundo" (84).

Ainda neste mesmo Capítulo 1 do Livro I, lemos na obra de Duarte Pacheco:

“...e com todo seu tormento grandemente povorada, por cuja causa se crê que os" etiópios são tão negros de color, por este círculo a eles ser propinco; e as últimas partes vezinhas aos polos, pola muita frialdade, dizem que a natureza desta região cria as gentes em subido grao d'alvura e fermosura;...".

Trata-se de passo também muito provàvelmente inspirado na seguinte expressão do Tratado de Sacrobosco, na sua tradução em língua portuguêsa:

"os ethiopyos nam seriam tam negros se en regiam temperada esteuesem" (85).

No Capítulo 2 dêste mesmo Livro I do Esmeraldo, lemos:

“...não era para duvidar a terra ser cercada pelas áuguas, e sòmente tirava ua pequena parte dela descoberta para a vida dos animais;...".

Passo ainda muito provàvelmente inspirado na seguinte frase do Tratado da Esfera:

(84). - Tbidem, pág. 35 .

(85). - Tbidem, pág. 52. 
"a sequidade da terra resiste : aa humidade da aguoa: pera a vida dalguños animaães” (86).

Ainda neste mesmo Capítulo 2 do Livro I do Esmeraldo, Pacheco escreveu:

"... assi que a áugua é posta na sétima parte da terra e as seis pärtes dela sáo descobertas pera a vida da. natureza humana e dos outros animais;...".

Uma vez mais lembramos o texto de Sacrobosco que aca-. bamos de citar, e que algumas relações tem com o texto de Duarte Pacheco:
"a sequidade da terra resiste aa humidade da aguoa pera a vida; dalguños animaães" (87.) .

No Capítulo 8 do Livro I, da obra de Duarte Pacheco, aparece uma expressão que volta a surgir no Capítulo 10 dêste mesmo Livro I, expressão que encontramos com bastante freqüên- . cia no texto de Sacrobosco:

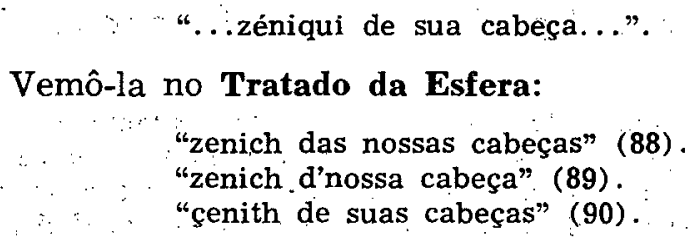

Săo expressões que também podemos ver nos textos latinos do Tratado da Esfera, sob a forma:

"cenith capitis nostris".

Finalmente, ainda neste mesmo Capítulo 8 do Livro I, da obra de Pacheco, lemos:

"...ourizom é onde nos" parece que se o céo ajunta com o mar ou com a terra; e este se chama detreminador de nossa vista, porque dali pera além não podemos: mais ver nada;...".".

Passo da obra de Duarte Pacheco que corresponde no, Tratado da Esfera de Sacrobosco à seguinte frase:

(86). - Tbidem, pág. 29.

(87). - Ibidem, pag. 29.

(88). - Tbidem, pág. 39.

(89). - Ibidem, p. 39.

(90). - Tbidem, oito exemplos nas págs. 50-51. 
"orzomte: q. quer dizer terminador de nossa vista" (91).

Nos textos latinos, lemos:

“orizon est circulus diuidens inferius emisperium a superiori. Unde appelatur orizon. scilicet. terminator visus...".

\section{(Continua) .}

(91). - Ibidem, pag. 40. 